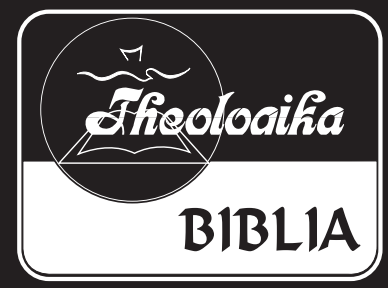

¿En qué ereyó Abram? El significado de

\author{
Génesis 15:6 \\ en su contexto
}




\section{Roy Graf}

Universidad Peruana Unión 


\section{RESUMEN}

“¿En qué creyó Abram? El significado de Génesis 15:6 en su contexto" - La declaración de Génesis 15:6, traducida usualmente "y creyó a Jehová, y le fue contado por justicia", se ha entendido como haciendo referencia al asentimiento de Abram a las promesas de Dios que aparecen en los versículos previos. Pero un análisis del texto, que tiene en cuenta el aporte de valiosos trabajos eruditos al respecto, revela que Abram está asintiendo a los términos del pacto que Dios le ofrece. Aquí se propone un análisis de este texto a la luz de su contexto inmediato, teniendo en cuenta distintos abordajes que permitan clarificar las dificultades presentes en el contexto y el texto mismo, a fin de determinar el significado y los temas teológicos que constituyen su trasfondo.

\section{SUMMARY}

"What did Abram believe in? The meaning of Genesis 15:6 in its context" - The assertion of Genesis 15:6, usually translated "and he believed the Lord; and he reckoned it to him as righteousness", has been understood as a reference to Abram's acceptance to God's promises that appear in the previous verses. However a careful study of the text, which has been studied also by many scholars, reveals that Abram is accepting the terms of a covenant that God is offering to him. This study proposes an analysis of this text according to its immediate context, considering different approaches that permit clarification of the actual difficulties in the context itself in order to determine the meaning and the theological themes that constitute its background. 


\section{¿EN QUÉ CREYÓ ABRAM? EL SIGNIFICADO DE GÉNESIS 15:6 EN SU CONTEXTO}

\section{Introducción}

Génesis 15:6 (traducido usualmente como “y creyó a Jehová, y le fue contado por justicia") representa un desafío en cuanto a la posibilidad de ofrecer sobre el mismo una interpretación "imparcial". ${ }^{1}$ La razón es que dicho texto ha sido objeto de múltiples interpretaciones posteriores y no siempre es fácil para el intérprete contemporáneo despojarse de todo el "bagaje" interpretativo acumulado en relación al mismo. Frecuentemente se ha considerado que el texto hace referencia al asentimiento de Abram a las promesas de Dios que aparecen en los vv. 1, 4 y 5, relacionadas especialmente con la descendencia de Abram. ${ }^{2}$ Desde

${ }^{1}$ Indudablemente, una interpretación nunca es completamente imparcial. Lo que se quiere destacar aquí es la dificultad adicional que este texto presenta en comparación con otros del Antiguo Testamento debido a la importancia que la tradición judeo-cristiana posterior le ha asignado al citarlo, con la intención de usarlo como base para construir argumentos teológicos sobre el mismo. Véase 1 Mac 2:52; Rom 4:3ss; Gál 3:6; Stg 2:23.

${ }^{2}$ Véase Alfred Jepsen, אָָז, en G. Johannes Botterweck y Helmer Ringgren, eds., Theological Dictionary of the Old Testament, ed. rev. (Grand Rapids, MI: Eerdmans, 1977), 1:307. En adelante, TDOT; Francis D. Nichol, ed., trad. Víctor Ampuero Matta “Creyó a Jehová” [Gén 15:6], Comentario bíblico adventista, (Mountain View, California: Publicaciones Interamericanas, 1978), 1:325. 
esta óptica, el resto del capítulo se ocuparía del tema del pacto de Dios con Abram. ¿Pero, es la fe en las promesas divinas el tema fundamental de este pasaje? Un escrutinio cuidadoso de este texto junto al aporte de valiosos trabajos eruditos sugiere que en realidad el tema de fondo es otro.

Aquí nos aproximaremos a Gén 15:6, teniendo en cuenta su contexto inmediato que incluye los vv. 1-5. ¿En qué creyó Abram? Veámoslo.

\section{El contexto de Génesis 15:1-6}

Génesis 15 se encuentra enmarcado en lo que se ha dado en llamar la "historia patriarcal" o segunda parte del libro de Génesis (11:27-50:26). ${ }^{3}$ Dentro de esta división principal del libro, el capítulo de la perícopa bajo estudio se encuentra ubicado en el ciclo de la historia de Abraham (11:27-25-18). ${ }^{4}$ Aecio Cairus ha hecho notar que el capítulo 15 se encuentra en el corazón de un patrón palistrófico o estructura quiástica que él sintetiza de esta manera:

${ }^{3}$ William Sanford Lasor, David Allan Hubbard y Frederic William Bush, Panorama del Antiguo Testamento. Mensaje, forma y trasfondo del Antiguo Testamento (Grand Rapids, MI: Libros Desafío, 2004), 85.

${ }^{4} I b i ́ d$. Coincide con esta subdivisión Terence E. Fretheim, "The Book of Genesis", en The New Interpreter's Bible (Nashville: Abingdon Press, 1994), 1:332-3. Véase también el bosquejo de Génesis que sugiere John H. Sailhamer, "Genesis", en Frank E. Gaebelein ed., The Expositor's Bible Commentary (Grand Rapids, MI: Regency Reference Library, 1990), 2:16-8, donde se propone que la narrativa de Abraham concluye en 25:11. Archer clasifica este capítulo a su vez dentro de la sección que él denomina "Renovación y confirmación del pacto" que él entiende va desde 15:1 a 17:27. Gleason L. Archer, Reseña crítica de una introducción al Antiguo Testamento, ed. rev. (Grand Rapids, MI: Editorial Portavoz, 1987), 198. 
A. Mandamientos divinos y obediencia de Abraham (11:27 a 12:9).

B. Amenaza a la esposa (12:10-20) y lucha de familia (13:1-3).

C. Revelación divina (13:14-18) y cuidado de Lot (cap. 14).

D. Pacto (cap. 15) y descendencia secundaria (cap. 16).

D' Pacto y descendencia secundaria (cap. 17).

$C^{\prime}$ Revelación divina (cap. 18) y cuidado de Lot (cap. 19).

B' Amenaza a la esposa (20) y lucha de familia (21). A'Mandamientos divinos y obediencia de Abraham (cap. 22). ${ }^{5}$

Como el propio Cairus señala, "este análisis del arreglo narrativo sugiere que el clímax del ciclo de Abraham aparece en los capítulos de pacto/promesa". ${ }^{6}$

Por otro lado, la conexión de este capítulo con el contexto inmediato se nota a través de fuertes vínculos retóricos y lingüísticos. Por ejemplo, la introducción "después de estas cosas" indudablemente hace referencia al relato anterior (capítulo 14) sobre la liberación de Lot por parte de Abram, la entrega de los diezmos a Melquisedec y la devolución del botín al rey

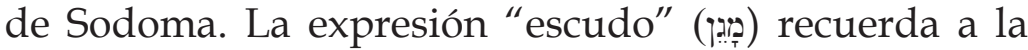
expresión traducida como "entregó" (מפִין) en 14:20, que

${ }^{5}$ Aecio E. Cairus, "Protection and Reward: The Significance of Ancient Midrashic Expositions on Genesis 15:1-6" (Tesis Doctoral, Andrews University, 1988), 242.

${ }^{6} I b i ́ d ., 243-4$. 
en hebreo comparten la misma raíz. La "recompensa" prometida (v. 1), en principio, parece ocupar el lugar del botín que Abram se negó a retener (14:23). ${ }^{7}$

Gén 15:1-6 se encuentra a su vez ubicado en una sección mayor que comprende todo el capítulo 15 (vv. 1-21). Los límites de esta sección mayor surgen de varios indicadores textuales. En primer término, Gén 15:1 inicia la misma con la expresión "después de estas palabras"

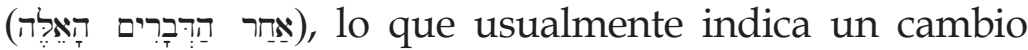
de tema. Además se produce aquí un cambio en los personajes. Dios no estaba presente en la sección anterior pero es introducido aquí iniciando un diálogo con Abram. Desapareceel rey deSodoma, mencionadoen los versículos precedentes (14:17-24). Otro factor a tener en cuenta es el sustancial cambio de tema. En los vv. anteriores del capítulo 15 la narrativa gira en torno a la devolución del botín de guerra de Abram al rey de Sodoma. El capítulo 15 se concentra en el pacto que Dios efectúa con Abram y en la promesa de Dios de darle descendencia. En cuanto al final de la sección mayor, se puede señalar que al iniciarse el capítulo 16 hay nuevamente un importante cambio de personajes. Desaparece Dios de la escena y se introducen Sarai y Agar. El foco de la historia es completamente distinto. Se abandona el tema del pacto entre Dios y Abram para hablar de la propuesta de Sarai de que Abram se allegue a Agar, sierva Sarai, para suplir la falta de hijos del matrimonio.

Los indicadores del texto masorético confirman también los límites sugeridos para el capítulo 15 en base

${ }^{7}$ Para estos y otros vínculos entre el capítulo 14 y el 15 véase Nahum M. Sarna, Genesis, The JPS Torah Commentary (Philadelphia, New York, Jerusalem: The Jewish Publication Society, 1989), 112. 
a los indicadores textuales. En el texto masorético, el capítulo 14 termina con una o (setumah) y el 15 termina también con una $\mathrm{o}$.

Se ha afirmado que esta sección mayor se subdivide en dos secciones principales, vv. 1-6 y 7-21, ${ }^{8}$ la primera de las cuales (vv. 1-6) presenta un "diálogo prepactual" 9 de Dios con Abram que incluye la promesa de Dios a Abram de un hijo y una descendencia numerosa y, la segunda (vv. 7-21), que presenta la consumación del pacto que incluye la promesa de Dios a Abram de que su descendencia heredaría la tierra donde estaban.

Desde un punto de vista literario, sin embargo, la sección mayor se puede subdividir en cuatro partes que representan el contexto más inmediato de la perícopa bajo estudio. La primera, ya mencionada, comprende los vv. 1-6 y termina con una "conclusión" que afirma que Abram confiaba en Dios (v. 6). La segunda, vv. 7-11, se

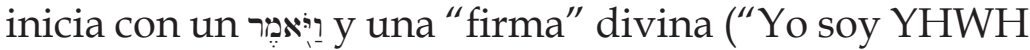
...") y en ella Dios le explica a Abram que prepare los elementos necesarios para la realización del ritual del pacto que confirmaría la herencia de la tierra, tarea que

${ }^{8}$ Ésta es la subdivisión que sigue por ejemplo John Skinner, $A$ Critical and Exegetical Commentary on Genesis, en Samuel Rolles Driver, Alfred Plummer y Charles Augustus Briggs, eds., 2da ed., The International Critical Commentary (Edinburgh: T\&T Clark, 1994 [última impresión]), 27684, quien titula a la primera parte como "La promesa de una herencia y una numerosa posteridad" (277) y a la segunda como "El pacto" (280). Skinner, sin embargo, basa esta subdivisión en la crítica de las fuentes. Para un autor que subdivide el texto de la misma manera pero apoya la unidad del capítulo 15 véase Gordon J. Wenham, Genesis 1-15, David A. Hubbard y Glenn Barker eds., Word Biblical Commentary (Waco, TX: Word Books, 1987), 1:325. En adelante $W B C$.

${ }^{9}$ Ésta es la denominación usada por Cairus en "Protection and Reward", 273, 424. 
Abram cumple fielmente. La tercera sección, vv. 12-16, se introduce con un indicador temporal ("y sucedió que el sol estaba por entrar") y trata del itinerario de la descendencia de Abram hasta la posesión de la tierra. La cuarta y última sección, vv. 17-21, es introducida por otro indicador temporal ("Y en aquel día..."). Presenta la consumación del pacto de Dios con Abram, donde se renueva la promesa de la herencia de la tierra y se establecen sus límites geográficos precisos. Se puede bosquejar sintéticamente esta estructura del capítulo 15 de la siguiente manera:

A. Diálogo pre-pactual que incluye la promesa de Dios de un hijo y una gran descendencia para Abram (vv. 1-6).

B. Preparativos para la realización del ritual pactual que confirma la herencia de la tierra (vv. 7-11).

C. El itinerario de la descendencia de Abram (vv. 12-16).

D. Consumación del pacto y establecimiento de los límites de la tierra (vv. 17-21).

Esta visión de conjunto del capítulo sugiere fuertemente la importancia del tema del pacto en todo el capítulo y no sólo a partir del v. 7 como a menudo se supone.

\section{El texto de Génesis 15:1-6: traducción y crítica textual}

La estructuración de la sección mayor (cap. 15) recién sugerida implica que los vv. 1-6 constituyen una 
unidad de sentido en sí misma, que se inicia con un

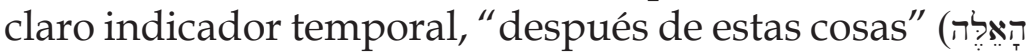

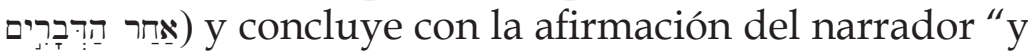
creía en Jehová y se le contó por justicia". ${ }^{10}$

Este texto ofrece algunas dificultades al traductor. Algunas de ellas se discutirán más adelante. Sin embargo, deseamos adelantar aquí una traducción para permitir al lector una visión de conjunto respecto al contenido del texto bajo análisis. Para ello es necesario tener en cuenta algunas dificultades presentadas en relación a la crítica textual. A fin de facilitar la identificación de los problemas textuales hemos colocado entre paréntesis los números que indican a su vez las notas correspondientes a la crítica textual que se encuentra a continuación de la traducción.

1. Después de estas cosas [palabras] vino [sucedió] palabra de Jehová a Abram en la visión diciendo: "no temas, Abram, yo soy escudo para ti; tu recompensa incrementaré [multiplicaré] (1) mucho".

2. Y dijo Abram: “Señor Jehová (2), ¿qué me darás, ya que yo sigo solo, sin hijo, y el heredero [" poseedor de mi casa"] es este Eliezer de Damasco (3)?"

3. Y dijo Abram: "he aquíno me diste descendencia y he aquí un hijo de mi casa está heredándome [recibiendo mi herencia]".

${ }^{10}$ Wenham llama al v. 6 "conclusión" de la sección 1-6 (Wenham, WBC, 1:325). Para él, el v. 6 se trata del "comentario editorial con el cual cierra la primera escena" (Ibíd, 329). Véase también George W. Coats, "Genesis with an Introduction to Narrative Literature", en Rolf Knierim y Gene M. Tucker, eds., The Forms of the Old Testament Literature (Grand Rapids, MI: Eerdmans, 1983), 122. 
4. Y he aquí (vino) palabra de Jehová para él diciendo: "no te heredará éste sino quien vendrá de tus entrañas, éste te heredará".

5. Y lo sacó afuera y dijo: "por favor mira los cielos y cuenta las estrellas si eres capaz de contarlas". Y le dijo: "así llegará a ser [tu] descendencia".

6. Y creía en Jehová y se le computó justicia. ${ }^{11}$

Como se puede percibir, las principales dificultades de crítica textual se concentran en los vv. 1 y 2. Ofrecemos detalles de los mismos a continuación.

(1) En el v. 1, el verbo que se traduce aquí como "incrementaré [multiplicaré]" se corresponde en el texto masorético con el verbo hiphil infinitivo

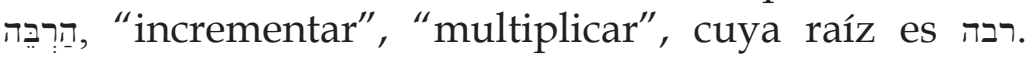
Según el texto samaritano debiera ser leído con אֶרֵּר hiphil imperfecto, primera persona del singular (es decir, "incrementar, incrementaré", o "ciertamente incrementaré"), que es la manera en que se presenta este verbo en otros pasajes como en Gén 16:10. Sin embargo, aquí preferimos la lectura del texto masorético por ser la más difícil. La variante del Pentateuco Samaritano es única y parece explicarse mejor como una corrección de una expresión inusual o incompleta del texto masorético.

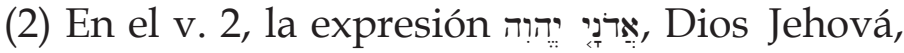

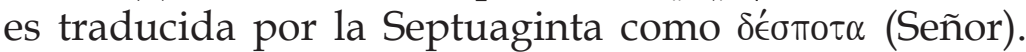
Sin embargo, esta variante no tiene apoyo de otros testigos textuales. Por otro lado, la misma no modifica sustancialmente el sentido del texto.

${ }^{11}$ Se tomó como base el texto de Elliger, K. y W. Rudolph eds. Biblia Hebraica Stuttgartensia, 5ta ed. (Stuttgart: Deutsche Bibelgesellschaft, 1997). 
(3) El aparato crítico de la Biblia Hebraica Stuttgartensia (BHS) señala que en el v. 2 una glosa aramea añade antes de "Eliezer" la expresión בן־משק, traducida en este mismo v. como "heredero". Esta añadidura no tiene apoyo, sin embargo, de ninguna otra familia importante de textos. Parece preferible la lectura más breve del texto masorético.

Una vez establecido el texto, es importante explorar brevemente algunos aspectos del contexto histórico del relato y del momento aproximado en el que se plasmó por escrito.

\section{El contexto histórico de Génesis 15:1-6: el trasfondo pactual}

Desde un punto de vista respetuoso del testimonio bíblico, la determinación del contexto histórico del relato patriarcal de Abraham se debe ubicar a principios del segundo milenio AC, en lo que se denomina la Edad de Bronce Media II. ${ }^{12}$ Si se tiene en cuenta la referencia cronológica de Gén 15:13 (en combinación con Éxo 12:40 y Gál 3:17) y se ubica el éxodo a mediados del siglo XV AC (como se desprende de 1 Rey 6:1), ${ }^{13}$ lo ocurrido en Gén 15 tiene que ubicarse durante el transcurso del siglo XIX AC.

Esta ubicación cronológica coincide con lo que se sabe del trasfondo cultural de Gén 15. En relación a

${ }^{12}$ Lasor, Hubbard y Bush, Panorama del Antiguo Testamento, 98.

${ }^{13}$ Con respecto a ubicación de la fecha del éxodo a mediados del siglo XV AC véase W. H. Shea, "Exodus, Date of the", en Geoffrey W. Bromiley, ed., The International Standard Bible Encyclopedia, reimp. (Grand Rapids, MI: Eerdmans, 1990), 2:230-238. 
15:2-4, por ejemplo, Wright explica que la mención que hace Abram de Eliezer como posible heredero se puede explicar a la luz de textos en las tablillas de Nuzi, según las cuales una pareja sin descendencia podía adoptar un hijo quien quedaba obligado a cuidar a sus padres y ocuparse de su sepultura cuando murieran a cambio de heredar las propiedades. El trato se modificaba solamente si nacía un hijo carnal. ${ }^{14}$

Más importante todavía para interpretar Gén 15 es comprender el trasfondo pactual de dicho capítulo a la luz de los pactos realizados en la antigüedad entre un soberano o conquistador poderoso y su rey o gobernante vasallo. "Éste es el tratado de soberanía por el cual un gran rey exigía a sus vasallos fidelidad y obediencia a sí mismo". ${ }^{15}$ Este tipo de tratados se pueden remontar a la época sumeria (tercer milenio AC) aunque la forma específica de los mismos es mejor conocida a partir de documentos hititas (1450-1200 AC) quienes a su vez parecen haberse basado en fuentes mesopotámicas anteriores. ${ }^{16}$ Estos tratados contenían frecuentemente promesas de ayuda y apoyo de parte del soberano hacia el vasallo frente a posibles amenazas de terceros estados, pero también implicaban "la obligación del vasallo a confiar en la benevolencia del soberano".${ }^{17}$ Es bastante conocida la estructura que los conformaba.

${ }^{14}$ G. E. Wright, Arqueología bíblica, trad. J. Valiente Malla (Madrid: Ediciones Cristiandad, 1975), 62.

${ }^{15}$ George E. Mendenhall, "Covenant Forms in Israelite Tradition", The Biblical Archaeologist 17: 3 (1954) 52.

${ }^{16}$ Ibíd., 53-54.

${ }^{17} I b i ́ d .$, 56. La cursiva es del original. 
Incluían (a) un preámbulo, que identificaba al soberano que efectuaba el pacto; (b) un prólogo histórico, que detallaba las acciones benevolentes del soberano a favor del rey vasallo; ${ }^{18}$ (c) las estipulaciones pactuales, que establecían las obligaciones impuestas sobre el vasallo, como por ejemplo la de que el vasallo no podía tener relaciones con otros poderes extranjeros, debiendo mantener una confianza ilimitada en el soberano, o la estipulación a la que el sucesor del vasallo debía también mantener la fidelidad al soberano, etc.; (d) provisiones para el depósito del tratado en el templo y para la lectura pública periódica del mismo; (e) una lista de dioses como testigos, y (f) las maldiciones y bendiciones resultantes del quebrantamiento o la fidelidad al pacto. ${ }^{19}$ Como se verá luego, algunas de estas características estructurales de los pactos pueden encontrarse en Gén 15, incluyendo los vv. 1-6.

En cuanto a la escritura del libro de Génesis (incluyendo obviamente a Gén 15), el mismo se debe situar en un período muy posterior al patriarcal, lo que es presupuesto por su propósito y destinatarios. En ese sentido se puede coincidir con Merling en cuanto a que "el propósito del libro de Génesis fue demostrar el cuidado protector de Dios para con su pueblo especial, los 'escogidos', y para animarlos a éstos en Egipto ya que precisaban de ese mensaje".$^{20}$ Esto implica como

${ }^{18} \mathrm{Al}$ respecto Mendenhall destaca que es importante "ver que el vasallo está cambiando obediencia futura a mandamientos específicos [del soberano] por beneficios pasados los cuales él recibió sin ningún derecho verdadero". Ibíd., 58.

${ }^{19}$ Ibíd., 58-60.

${ }^{20}$ David Merling, "El libro de Génesis: sus preocupaciones y contextos internos", en Merling Alomía, Segundo Correa, Víctor Choroco 
trasfondo histórico del libro la situación de los israelitas como esclavos en Egipto, quienes necesitaban saber desesperadamente que su presencia allí no había sido accidental, no habían sido olvidados a pesar de su situación de aparente desamparo y serían redimidos ya que formaban parte del linaje escogido. ${ }^{21} \mathrm{El}$ Dios del pacto, Jehová, el mismo que hizo el pacto con Abram en Génsis 15 es el que se presenta como el libertador de su pueblo escogido (Éxo 3:13-14).

\section{Claves literarias de Génesis 15:1-6}

Es necesario revisar algunas aspectos literarios de Génesis 15:1-6 con miras a desentrañar el significado de su declaración final (v. 6). Estos aspectos incluyen la estructura interna de la perícopa, el género y el estilo literario, un breve análisis de la caracterización y del flujo de la narración, así como también de las dificultades sintácticas y semánticas involucradas.

\section{La estructura literaria de Gén 15:1-6}

Gén 15:1-6 posee una definida estructura que permite establecer cinco subdivisiones en función de sus indicadores textuales internos:

A. Jehová promete a Abram protección y recompensa (v. 1).

B. Reclamo de Abram a Dios por no tener un hijo (vv. 2-3).

y Edgard A. Horna, eds., Volviendo a los orígenes: Entendiendo el Pentateuco (Lima: Ediciones Theologika, Lima, 2006), 543.

${ }^{21}$ Ibíd., 544-550. 
C. Reacción de Jehová prometiéndole un hijo a Abram (v. 4).

D. Dios promete una descendencia numerosa (v. 5).

E. Abram cree en las promesas de Dios y éste lo considera justo (v. 6).

La primera subdivisión se introduce con el indicador textual que a su vez introduce todo el capítu-

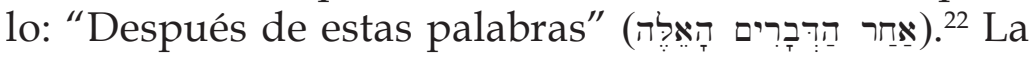
segunda subdivisión se introduce con la expresión "y

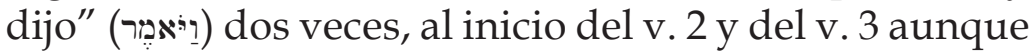
ambos vv. tratan del reclamo de Abram a Dios por no tener un hijo. La forma reiterativa podría sugerir que la reacción de Abram se dio, en realidad, en dos momentos sucesivos separados por un lapso de tiempo. ${ }^{23} \mathrm{El} \mathrm{v}$. 4 contiene la tercera subdivisión introducida por la

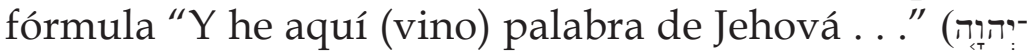

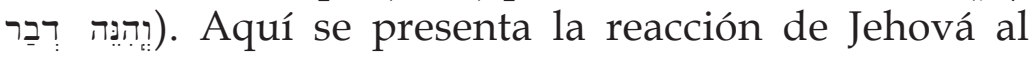
reiterado reclamo de Abram. La cuarta subdivisión (v. 5) es distinguida por un cambio de lugar ("Y lo sacó afuera") seguido de un nuevo וַיאוּ ("y dijo"). La quinta y última sección, en el v. 6, es, como ya se mencionó, una conclusión narrativa de toda la perícopa. No forma parte de los diálogos previos entre Dios y Abram. Su ubicación sugiere que ésta es una cláusula del autor

${ }^{22}$ Esta frase es un claro delimitador textual utilizado para introducir una nueva narración o una sección nueva de una narración como se puede observar en el mismo libro de Génesis (22:1; 39:7; 40:1). Véase también 1 Rey 17:17; 21:1; Est 2:1; 3:1.

${ }^{23}$ Lo cual no sería extraño en el contexto del capítulo donde pareciera que los sucesos narrados se dan en diferentes momentos. Por ejemplo, en el v. 5 es evidente que Dios habla con Abram de noche, en tanto que el diálogo que Dios inicia con Abram a partir del v. 7 ocurre en otro momento, durante las horas de luz de un día (comparar con vv. 12, 17). 
que sintetiza la reacción de Abram al ofrecimiento de Dios de protección y recompensa (A, v. 1).

\section{El género literario de Génesis 15:1-6}

En una primera aproximación Gén 15 parece un texto narrativo, ubicado a su vez en un contexto narrativo mayor (ver capítulos 14 y 16). Coats ha argumentado en contra de esta postura, pues para él Gén 15:1-6 (y también Gén 15:7-21) es mejor definido como un diálogo de promesa ${ }^{24}$ o como una unidad que "es simplemente un diálogo, estructurado sobre la base de un oráculo de salvación" ${ }^{25}$ Coats ha señalado a favor de esta postura, que la perícopa no revela ni las escenas ni el argumento propio de un relato, ${ }^{26}$ lo que se esperaría de una narración. Sin embargo, Coats construye indudablemente sobre las premisas de la crítica de las formas y presupone además la crítica de las fuentes, lo que le hace suponer que la perícopa representa un ensamble de distintas unidades literarias a las que les falta coherencia natural.

Por otro lado, este punto de vista es discutible, pues la perícopa no sólo se inicia con una fórmula narrativa ("después de estas cosas ... ") sino que además genera una tensión narrativa debido a que la pregunta de Abram en el v. 2 queda sin responder. En el v. 3 Abram se expresa en términos de una virtual queja, lo que aumenta la tensión. Esta tensión llega a

\footnotetext{
${ }^{24}$ Coats, Genesis with an Introduction to Narrative Literature, 122.

${ }^{25}$ Ibíd, 125.
}

${ }^{26} I b i ́ d, 122$. 
su punto culminante en el v. 4 donde Dios finalmente responde a Abram, lo cual conduce a una distención (resolución) y a la posterior "conclusión" del v. 6.

Además, como se puede apreciar, a pesar del carácter dialógico de la perícopa, ésta tiene los rasgos propios de un relato. Hay un evento que desencadena la acción (Dios se presenta a Abram en visión), protagonistas (Dios, Abram), un "héroe" (Abram, el que llega a creer), diferentes escenas o momentos (como se pueden apreciar en la estructura de la perícopa ya descrita), un posible "antihéroe" (Eliezer, potencialmente beneficiado por la imposibilidad de Abram de tener hijos), una secuencia argumentativa que a su vez encaja perfectamente en el relato completo de la vida de Abram (¿cómo haría Dios de Abram una nación grande [12:2-3] si ni siquiera tenía hijos?), se percibe la presencia del narrador (v. 6) y el relato posee la concisión típica de la narrativa hebrea del Antiguo Testamento. ${ }^{27}$

Al mismo tiempo, Cairus se refiere a Gén 15:16 como un "diálogo pre-actual", ${ }^{28}$ el cual es la esencia de la narración. Y éste es un dato fundamental. Cairus encuentra en esta sección posibles indicadores de la estructura de un pacto antiguo. ${ }^{29}$ Así por ejemplo, en

${ }^{27}$ Se están teniendo en cuenta aquí algunas de las características distintivas de la narrativa bíblica presentadas en V. Philips Long, "Reading the Old Testament as Literature", en Craig C. Broyles, ed. Interpreting the Old Testament: A Guide for Exegesis (Grand Rapids, MI: Baker Academic, 2001), 106-9.

${ }^{28}$ Cairus, "Protection and Reward", 273.

${ }^{29}$ Para Cairus, Gén 15:1-6 presenta una cuádruple división típica de diálogos pre-pactuales: (a) invitación a la relación (v. 1), (b) pregunta de la otra parte (vv. 2-3), (c) satisfacción del cuestionamiento (vv. 4-5), y (d) 
el v. 1 Jehová se identifica como el soberano protector a través de la expresión "yo soy tu escudo". Este preámbulo "toma la forma de una autorrevelación de Yahvé". ${ }^{30}$ Por otro lado, a pesar de que no hay un preámbulo o prólogo histórico formal, las conexiones de términos de este pasaje "con favores previos de Dios, incluyendo la victoria reciente sobre los cuatro reyes, funciona con el mismo efecto". ${ }^{31} \mathrm{Y}$, aunque no hay estipulaciones pactuales explícitas en relación a Abram mismo, la fidelidad demostrada por Abram en el contexto previo es justamente la fidelidad que el pacto busca asegurar. ${ }^{32}$ Pero las estipulaciones sí son explícitas con respecto al papel de Dios. Jehová se obliga a sí mismo a proveer protección y recompensa, invitando a Abram a confiar en él. "La admonición a no temer, seguida por la autorrevelación de Dios como Protector, claramente tiene el carácter de una invitación a confiar en él (parte íntegra de las estipulaciones de los antiguos tratados de soberanía)" ofrecimiento que es aceptado por Abram (v. 6). ${ }^{33}$ A su vez las expresiones, "escudo"

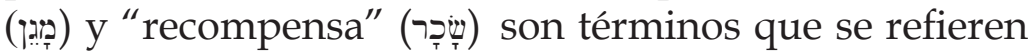

aceptación (v. 6). Una estructura similar puede encontrarse en otros textos veterotestamentarios que son de carácter explícitamente pactual (Gén 15:721; 21:22-32; Jos 9:6-15, etc.), lo que confirma el carácter pactual de Gén 15:1-6. Véase Cairus, 271-273.

${ }^{30} I b i ́ d, 269$. Ver también Ibíd, 270.

${ }^{31}$ Ibíd., 269.

${ }^{32}$ Ibíd.

${ }^{33} I b i ́ d ., 269-270$. Que la expresión "no temas" (Gén 15:6) tiene connotaciones pactuales surge de la comparación con otros pasajes bíblicos tales como Gén 21:7-8; 26:24; Isa 41:8-10; 43:1, 5, 10. Véase Cairus, 421-424. 
a la oferta de protección y recompensa (por ejemplo de tierras) de un soberano hacia su vasallo en el contexto de un pacto. ${ }^{34}$

Un aspecto más a destacar en relación al género literario es lo que Gary A. Rendsburg ha señalado en cuanto a la posibilidad de que el v. 1 incluya también poseía, en la declaración de Dios a Abram. ${ }^{35}$ Sobre esto volveremos más adelante. Por lo pronto, sin embargo, se trataría de una poesía insertada en un contexto narrativo.

\section{Aspectos estilísticos de Génsis 15:1-6}

Como se ha mencionado, el texto es de carácter narrativo, escrito básicamente en prosa (con la posible excepción de las palabras de Jehová del v. 1). Esto implica la existencia de frecuentes fórmulas narrativas ("después de estas cosas", "y dijo", "y vino palabra de Jehová") y la utilización abundante de los verbos qal perfecto en tercera persona ("sucedió", v. 1; "creyó", v. 6) o verbos qal imperfecto en tercera persona singular con waw consecutiva ("y dijo", vv. 2, 3, 5; "y trajo fuera", v. 5; "consideró", v. 6), típicos de la prosa narrativa. Los verbos en segunda persona, ya sean en imperativo

${ }^{34}$ Cairus, 277. Según Cairus, "la recompensa debería ser concebida como la totalidad de los privilegios con los cuales Abraham fue investido como el vasallo del Señor", 388-389.

${ }^{35}$ Gary A. Rendsburg, "Notes on Genesis XV", Vetus Testamentum 42:2 (1992) 266-8. Su argumentación se basa en la probable existencia de un recurso poético llamado "paralelismo de Jano" ("Janus Parallelism") en la declaración de Dios a Abram en el v. 1, como se explicará en el análisis estilístico. 
("no temas", v. 1; "mira", v. 5) o en qal ("darás", v. 2; “diste", v. 3), son frecuentes en los diálogos como es de esperarse y resaltan los roles de cada personaje.

La perícopa incluye la utilización de varios recursos literarios. Como se señaló antes, Rendsburg sostiene que la promesa de Jehová a Abram en el v. 1 es en realidad poesía y no prosa. ${ }^{36}$ En ese caso los "versos" podrían presentarse así:
"No temas, Abram,
yo soy escudo para ti;
tu recompensa incrementaré mucho".

Esta porción poética incluye además la utilización de lo que se denomina "paralelismo de Jano" ${ }^{37}$ según el cual el término que se traduce como "escudo" (מָָּן puede interpretarse simultáneamente, a partir de sus consonantes, como "dar" o "dador", que en hebreo posee las mismas consonantes (מגן). En este recurso, el mismo término es utilizado con dos significados distintos, uno en paralelo a una primera cláusula (en este caso, "yo soy tu escudo") y otro en paralelo a una segunda ("tu recompensa incrementaré ..."). En ese caso, la promesa de Jehová a Abram le estaría diciendo no sólo que Él es su escudo, sino que Jehová es también el que le dará la recompensa a Abram. A través de este recurso retórico

\section{${ }^{36}$ Rendsburg, "Notes on Genesis XV", 267.}

${ }^{37}$ Jano era un dios de la mitología romana que poseía dos caras mirando hacia lados opuestos. 
se destaca que Jehová mismo es el que garantiza no sólo protección, sino también recompensa para Abram. ${ }^{38}$ Ambos aspectos van juntos, son inseparables; la ausencia de cualquiera de los dos haría que el ofrecimiento pactual de Dios a Abram fuese incompleto.

Otro recurso estilístico presente en la perícopa es el lenguaje figurado. Dios le dice a Abram que es su "escudo" (v. 1), lo cual es una metáfora utilizada para destacar el papel protector de Jehová en relación a Abram. A su vez la "recompensa" que se multiplicará (v. 1) es en realidad una metáfora que por anticipación designa los beneficios ofrecidos a Abram como resultado de la concertación del pacto, los cuales probablemente incluyen tierras y descendencia. ${ }^{39}$ Una tercera figura del lenguaje se puede encontrar en el v. 5 donde las estrellas son presentadas como un símil utilizado para subrayar lo innumerable de la descendencia de Abram.

\section{Caracterización y flujo de la narración}

Génesis 15:1-6 está constituido por un conjunto de personajes y elementos que desarrollan papeles definidos en diferentes "momentos" y "escenarios" de la narración. A continuación presentamos un cuadro que permite observar en una mirada cómo están integrados en el relato los personajes y sus roles, los elementos y sus roles, los momentos que se suceden y los escenarios o lugares (en el sentido retórico).

${ }^{38}$ Rendsburg, 266-7.

${ }^{39}$ Véase Cairus, 388-9. 


\begin{tabular}{|c|c|c|c|c|c|}
\hline $\begin{array}{r}\text { Momento } \\
/ \text { lugar }\end{array}$ & $\begin{array}{l}\text { Momento } 1 \\
\text { (vv. 1-2) }\end{array}$ & $\begin{array}{l}\text { Momento } 2 \\
\text { (v. 3) }\end{array}$ & $\begin{array}{c}\text { Momento } 3 \\
\text { (v. } 4)\end{array}$ & $\begin{array}{l}\text { Momento } 4 \\
\text { (v. 5) }\end{array}$ & $\begin{array}{c}\text { Momento } 5 \\
\text { (v. 6) }\end{array}$ \\
\hline $\begin{array}{c}\searrow \\
\text { Personaje } \\
\text { /elemento }\end{array}$ & "En la visión" & $\begin{array}{l}(\text { Sin } \\
\text { referencia a } \\
\text { lugar) }\end{array}$ & $\begin{array}{l}\text { (Sin referencia a } \\
\text { lugar. Pero hay } \\
\text { una segunda } \\
\text { manifestación } \\
\text { de la palabra de } \\
\text { Jehová) }\end{array}$ & $\begin{array}{l}\text { "Y lo sacó } \\
\text { afuera" }\end{array}$ & $\begin{array}{l}(\text { "En } \\
\text { Jehová") }\end{array}$ \\
\hline $\begin{array}{l}\text { [Palabra de] } \\
\text { Jehová }\end{array}$ & $\begin{array}{l}\text { - Viene a Abram } \\
\text { (palabra de } \\
\text { Jehová) } \\
\text { - Le dice a Abram } \\
\text { que no tema, que } \\
\text { será su escudo y } \\
\text { que incrementará } \\
\text { su recompensa, } \\
\text { proponiéndole } \\
\text { así entrar en una } \\
\text { relación de pacto. }\end{array}$ & & $\begin{array}{l}\text { - Le dice a } \\
\text { Abram que el } \\
\text { heredero será } \\
\text { un hijo suyo. }\end{array}$ & $\begin{array}{l}\text { - Lleva afuera } \\
\text { a Abram. } \\
\text { - Le dice que } \\
\text { cuente las } \\
\text { estrellas si } \\
\text { puede. } \\
\text { - Le dice que } \\
\text { así será su } \\
\text { descendencia. }\end{array}$ & \\
\hline Abram & $\begin{array}{l}\text { - Pregunta a Dios } \\
\text { qué se le dará } \\
\text { para garantizar } \\
\text { la continuidad } \\
\text { del pacto ya que } \\
\text { no tiene hijos y } \\
\text { su heredero es } \\
\text { Eliezer. }\end{array}$ & $\begin{array}{l}\text { - Le dice a } \\
\text { Dios que no } \\
\text { le ha dado } \\
\text { descendencia } \\
\text { (lo que no } \\
\text { permitiría } \\
\text { garantizar la } \\
\text { continuidad } \\
\text { del pacto con } \\
\text { sus descen- } \\
\text { dientes) y que } \\
\text { un hijo de su } \\
\text { casa le está } \\
\text { heredando. }\end{array}$ & & & $\begin{array}{l}\text { - Creyó en } \\
\text { Jehová como } \\
\text { su protector } \\
\text { y benefactor } \\
\text { y le fue } \\
\text { considerada } \\
\text { su fe como } \\
\text { justicia. }\end{array}$ \\
\hline $\begin{array}{l}\text { Descen- } \\
\text { dencia de } \\
\text { Abram }\end{array}$ & $\begin{array}{l}\text { - No le ha sido } \\
\text { dada a Abram } \\
\text { por Dios para dar } \\
\text { continuidad al } \\
\text { pacto. } \\
\text { - Prometida } \\
\text { implícitamente } \\
\text { como recom- } \\
\text { pensa. }\end{array}$ & & & $\begin{array}{l}\text { - Dios dice de } \\
\text { ella que sería } \\
\text { como las } \\
\text { estrellas del } \\
\text { cielo. }\end{array}$ & \\
\hline Eliezer & $\begin{array}{l}\text { - Mencionado por } \\
\text { Abram como el } \\
\text { heredero. }\end{array}$ & $\begin{array}{l}\text { - Será el } \\
\text { heredero de } \\
\text { Abram. }\end{array}$ & $\begin{array}{l}\text { - No heredará a } \\
\text { Abram. }\end{array}$ & & \\
\hline $\begin{array}{l}\text { Un hijo de } \\
\text { Abram }\end{array}$ & $\begin{array}{l}\text { - No es tenido } \\
\text { por Abram. }\end{array}$ & $\begin{array}{l}\text { - No es tenido } \\
\text { por Abram. }\end{array}$ & $\begin{array}{l}\text { - Será el que } \\
\text { heredará a } \\
\text { Abram. }\end{array}$ & & \\
\hline
\end{tabular}


Los lugares exactos de los diálogos no son declarados más que en términos retóricos ("en visión”, v. 1; "y lo sacó afuera", v. 4). Pero los diferentes "lugares" o "momentos" sugieren que las interacciones entre Jehová y Abram abarcaron cierto tiempo. Los personajes centrales son obviamente Jehová y Abram. Jehová es el que desencadena los acontecimientos proponiéndole a Abram un pacto. Su interés está puesto en Abram, pero no por méritos intrínsecos de éste sino en virtud de la descendencia que provendría de él y para la cual Dios tiene un propósito más amplio, aunque este último no está explícito en el texto. Por otro lado, al principio Abram parece interpretar "descendencia" en términos de "hijo" (comparar vv. 2 y 3) pero no en un sentido corporativo y que se extiende en el futuro. Cabe aclarar que Abram no está reclamando beneficios adicionales del pacto de Dios con él al inquirir por su descendencia, sino que busca entender cómo el pacto que Dios le ofrece será posible, pues la descendencia era una manera de garantizar los términos del pacto. ${ }^{40}$ Abram asume entonces que la "recompensa" de Dios está relacionada con la herencia en manos de un hijo todavía ausente. Y esta ausencia le molesta (véase la expresión "este Eliezer de Damasco"). Sin embargo, el "hijo" todavía no tenido por Abram que aparece en los primeros tres momentos (vv. 2-3, 4), finalmente desaparece por completo de la perícopa (y de todo el capítulo en realidad) para dar lugar solamente al concepto de "descendencia". Dios desea que Abram comprenda que sus propósitos son más

${ }^{40}$ Cairus, 403. "Una garantía pactual apunta a una relación estable del suzerain, no hacia un individuo meramente, sino hacia su linaje completo". Ibíd. 
amplios y de mayor alcance que lo que Abram imagina. La recompensa que se le ofrece (v. 1) alcanza en realidad a su descendencia. Pero Abram puede apropiarse de ella sólo por la fe (v. 6), pues no vivirá para verlo (véase v. 15). El protagonismo de Abram pasa del reclamo a la fe en la promesa divina de protección y recompensa. ${ }^{41}$

\section{Dificultades sintácticas y semánticas del texto}

La perícopa presenta algunas dificultades en cuanto a su comprensión desdeel punto de vista sintáctico y semántico. Por lo tanto, algunas puntualizaciones son necesarias.

Un primer aspecto es la traducción de cuyo significado, sin embargo, no es esencial en la comprensión del texto. La misma se presenta como problemática en varios léxicos. En el contexto de Gén 15:2 se lo ha definido como "posesión". ${ }^{42}$ Wenham propone la traducción "heredero", pues interpreta la

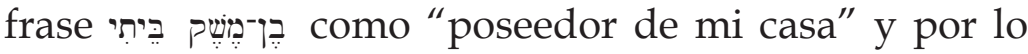
tanto "heredero" ${ }^{43}$ El contexto también parece ir a favor de esta última interpretación.

Las otras dos dificultades que merecen destacarse son de orden sintáctico. En primer lugar, en el v. 6, el

${ }^{41}$ Véase Cairus, 395.

${ }^{42}$ Luis Alonso Schökel, Diccionario completo de Hebreo-Español (Valladolid: Editorial Trotta, 1994), s.v. פְּ Alonso Schökel reconoce sin embargo que el significado del término es dudoso. De hecho, Holladay lo deja sin explicación. William L. Holladay, A Concise Hebrew and Aramic Lexicon of the Old Testament, reimpr. (Leiden: Brill, 2000), קֶ:

${ }^{43}$ Wenham, Genesis 1-15, 328. 
término והאירמן, es un hiphil perfecto tercera persona masculino singular con waw conjuntiva, aunque lo usual sería waw consecutiva más imperfecto. Esto probablemente indica una acción repetida o continua en el pasado ("creía"), por contraste a una acción puntual ("creyó"). ${ }^{44}$ En este caso el verbo "sería más adecuadamente traducido como 'y él continuaba creyendo' [creía] más bien que 'y creyó'”" 45

La segunda dificultad sintáctica radica en la determinación del sujeto del verbo חָד ("consideró", "computó") en el v. 6. Hay una cierta incertidumbre en cuanto al sujeto del verbo. Puede ser el sujeto del verbo precedente ("creyó"), en cuyo caso sería Abram, o puede ser Dios. Si el sujeto fuera Abram, entonces la "justicia" se referiría a los actos de Dios. En esta última dirección, se pronuncia Lloyd Gaston, para quien el texto puede ser entendido en términos del paralelismo hebreo, donde la primera cláusula ("y creía en Jehová") sería paralela a la segunda ("y le atribuyó a él justicia"). ${ }^{46}$ Su implicación es que en ese caso ambas cláusulas podrían tener el

${ }^{44} I b i d, 324$.

${ }^{45}$ Max Rogland, “Abram's Persistent Faith: Hebrew Verb Semantics in Genesis 15:6", Westminster Theological Journal 70 (2008) 239.

${ }^{46}$ Lloyd Gaston, "Abraham and the Righteousness of God", originalmente publicado en Horizons in Biblical Theology. An International Dialogue, vol. 2 (1980), http://www.jcrelations.net/en/?id=752 (consultado: 2 de marzo, 2009). Cabe aclarar que las apreciaciones de Gaston están fuertemente motivadas por una agenda de diálogo interreligioso entre cristianos y judíos. Gaston considera que la forma en que Gén 15:6 es interpretado en el Nuevo Testamento ha condicionado la lectura del pasaje en su contexto original. Sin embargo, aun intérpretes judíos contemporáneos como Nahum M. Sarna han considerado que "Dios es el sujeto del verbo" y no Abram. Sarna, Genesis, 113. 
mismo sujeto (Abram). Sin embargo, "la cuestión no puede decidirse simplemente a partir de la gramática del versículo mismo". ${ }^{47}$

Esto se debe a que "bajo la regla gramatical general de que un pronombre se refiere a su antecedente más cercano, parecería que fue Dios quien le estaba atribuyendo justicia a Abram". ${ }^{48}$ Además, aunque la secuencia de verbos favorecería a Abram como el sujeto, el contexto favorecería a Dios. ${ }^{49}$

Es útil tener en cuenta además que el término , צִדרקה , "justicia", en el Pentateuco, siempre se aplica a la actividad humana. ${ }^{50} \mathrm{El}$ estrecho paralelismo con Sal 106:31 favorece esta última interpretación. ${ }^{51}$ El v. 31 se refiere a Finees (ver Núm 25:7-13) de quien se dice literalmente: "y se le contó a él (niphal) por justicia". El sujeto tácito de la acción indudablemente es Dios (comparar con Núm 25:11-13). ${ }^{52}$

${ }^{47}$ J. Gerald Janzen, Abrahamand All the Families of the Earth: A Commentary on the Book of Genesis 12-50, International Theological Commentary (Grand Rapids, Edinburgh: Eerdmans, Handsel Press, 1993), 39.

${ }^{48}$ Daniel A. Klein, “Who Counted Righteoussness to Whom' Two Clashing Views by Shadal on Genesis 15:6", Jewish Bible Quarterly 36:1 (2008) 29.

${ }^{49}$ Véase John E. Hartley, בשח, en Willhem A. vanGemeren, ed., New International Dictionary of Old Testament Theology and Exegesis (Grand Rapids, MI: Zondervan, 1997), 2:306.

${ }^{50}$ Véase Wenham, Genesis 1-15, 330. Véase Gén 18:19; 30:33; Deu $6: 25 ; 9: 4-6 ; 24: 13 ; 33: 21$.

${ }^{51}$ Wenham, Genesis 1-15, 329, 330.

${ }^{52}$ Cairus destaca que ("considerar", "computar") no se utiliza en contextos doxológicos en la Biblia hebrea (es decir para alabar a Dios por parte de seres humanos, como sería el caso aquí si el sujeto del verbo fuese Abram), lo que hace muy improbable su uso con este sentido aquí. Cairus, 
En este punto, puede ser útil una comparación con la Septuaginta. Esta versión traduce Gén 15:6

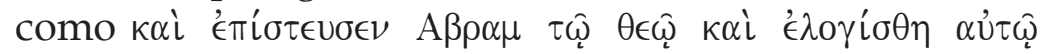

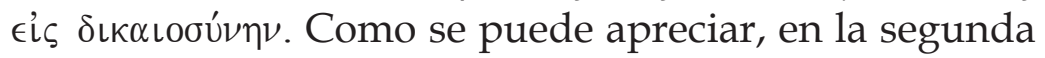

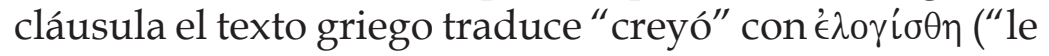
fue contado") aoristo pasivo tercera persona singular de

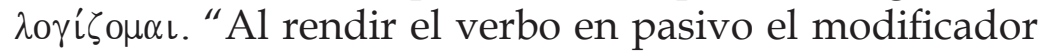
dativo $[\alpha \dot{v} \tau \hat{\omega}]$ debe ser Abram, con el sujeto indefinido entendido como el de la cláusula precedente, i.e. Abram es el que cree en Dios. La transformación pasiva remueve toda posible ambigüedad del pasaje". ${ }^{53}$

Desde el punto de vista semántico, hay tres términos que revisten singular importancia en la comprensión de esta perícopa. Los tres se encuentran en el v. 6, a manera de conclusión. El primero de ellos es אמן, el cual aparece por primera vez aquí en el Antiguo Testamento. Como ya se mencionó, se trata de un verbo en hiphil perfecto, tercera persona masculina singular con waw conjuntiva. Su significado básico en hiphil es muy diverso e incluye "creer, fiarse, confiar, fiar, dar crédito, ponerse en manos de, contar con, esperar, dar $\mathrm{fe}^{\prime \prime} .{ }^{54}$ Jepsen, luego de una extensa discusión sobre el significado del verbo אמן en su voz hiphil, concluye que el mismo "contiene una declaración acerca del sujeto que gana confianza, mayormente con referencia a una persona o a un mensaje".$^{55}$ En el contexto de Gén 15:6,

334, 335 35 John William Wevers, Notes on the Greek Text of Genesis, Society of Biblical Literature. Septuagint and Cognate Studies Series 35 (Atlanta: Scholars Press, 1993), 206.

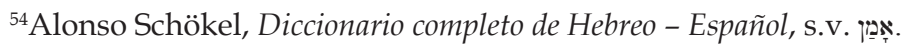

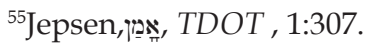


Abram reacciona a la promesa de Yahvé y a su alusión a las estrellas al tomar esta promesa de Dios seriamente, por confiar en ella o, para ser más específico, por confiar en Dios y creer que él es capaz de cumplir su promesa. Aunque es a menudo muy difícil confiar en el hombre, es todavía posible confiar en Dios. Ésta es la única posible conducta correcta hacia Dios y, por lo tanto, es considerada por Dios como tal. ${ }^{56}$

Cairus destaca, sinembargo, quelomásimportante "frente a lo cual Abram debe fijar su posición" no es la promesa de Jehová sino "la oferta del pacto (protección y dignidad). Por lo tanto, 'creyó Abraham a Dios' no significa primordialmente que creyó que habría de tener un hijo... sino que creyó en Dios como su protector y salvador personal". ${ }^{57}$

El segundo término que requiere una consideración especial es vez en la Biblia Hebrea. Este verbo aparece como un qal tercera persona masculino singular con waw conjuntiva. En esta misma voz y, cuando posee un predicado, los significados básicos pueden ser "considerar, estimar, creer, tomar por". ${ }^{58}$ Seybold propone que desde el punto de vista semántico puede haber dos significados básicos. Uno es el de contar, computar, contar, valuar, calcular; el otro sería el de elaborar, concebir, inventar. ${ }^{59} \mathrm{El}$ primer significado básico parece coincidir

${ }^{56}$ Ibíd., 305.

${ }^{57}$ Aecio E. Caïrus, La epístola a los Romanos. Exégesis en el Nuevo Testamento (Villa Libertador San Martín, Entre Ríos: Universidad Adventista del Plata, 1993), 81.

${ }^{58}$ Alonso-Schökel, s.v. חשַָׁ. 
más con el contexto de Gén 15:6. Alonso-Schökel coloca al uso de este verbo en Gén 15:6 como ejemplo para las acepciones de "computarle como mérito, apuntarle a su haber" lo que haría alusión a un lenguaje comercial. ${ }^{60}$ El contexto avala esta interpretación ya que el lenguaje comercial está presente. Así encontramos la promesa de una gran recompensa (v. 1), la cuestión de cómo se "pagaría" esa recompensa (v. 2), la "negociación" acerca de la propiedad y la herencia (el verbo ירָר ocurre tres veces en los vv. 3-4) y la demostración de números (v. 5). El reconocimiento de la fe de Abram como justicia "documenta la conclusión de la transacción". ${ }^{61}$

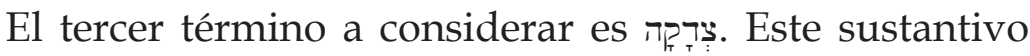
femenino singular aparece aquí por primera vez en el Antiguo Testamento. En términos generales se puede definir como "justicia, derecho, honradez, rectitud; mérito, crédito; justificación, inocencia, generosidad, limosna". ${ }^{62}$ En el contexto de Gén 15:6 sería mejor definido como crédito o haber. ${ }^{63}$ Johnson sostiene que el término se refiere, sobre todo, a "la intervención positiva y benefactora" de Jehová. ${ }^{64}$ En Génesis 15 Dios propone un pacto a Abram acompañado de la promesa de tener un hijo. Abram asiente afirmativamente al pacto, cree en

\footnotetext{
${ }^{59} \mathrm{~K}$. Seybold,

${ }^{60}$ Alonso-Shökel, Ibíd.

${ }^{61} I b i ́ d, 243$.

${ }^{62}$ Alonso-Schökel, s.v. צִדְָּז

${ }^{63}$ Ibíd.
}

${ }^{64}$ B. Johnson, en TDOT (2003), 12:253. 
la promesa y Dios se lo reconoció como justicia. ${ }^{65}$ Esto no está en contradicción con lo dicho anteriormente de que la palabra "justicia", en el Pentateuco, siempre se aplica a la actividad humana. ${ }^{66}$ La idea es que Dios es el que atribuye a Abram justicia. Dios está involucrado como el que atribuye justicia, pero Abram como el que es objeto de esa atribución y quien se apropia de esa justicia a través del recurso de su creencia.

\section{Los temas teológicos en Génesis 15:1-6}

En Gén 15:1-6 se destacan varios temas teológicos importantes. Pero el más importante de ellos es el del pacto. Éste es el tema que domina toda la sección. Todos los otros temas como promesas, descendencia y fe, están ligados a éste. Dios ofrece a Abram un pacto y éste debe decidir cuál será su actitud frente a él. Las promesas de proteccióny recompensa(v.1)constituyenelcompromiso de Dios que forma parte de las estipulaciones del pacto. A su vez, la promesa de descendencia era una extensión de los beneficios concedidos al entrar en relación pactual. La descendencia "está realmente subordinada a las promesas que acompañan la auto-protección de Yahvé, es decir protección y recompensa" ${ }^{67}$ Si Abram no tenía descendencia, la continuidad de los términos del pacto se truncaba. ${ }^{6}$ La descendencia es pues un prerrequisito

${ }^{65}$ Véase Ibíd.

${ }^{66}$ Véase Wenham, Genesis 1-15, 330.

${ }^{67}$ Cairus, "Protection and Reward", 395.

${ }^{68}$ Véase Cairus, La epístola a los Romanos, 81. En las estipulaciones de un pacto entre un soberano y un vasallo, se solía establecer que los 
para la continuidad del pacto. Cuando Abram entendió que éste estaba dado, pudo creer o confiar en Dios como su protector y benefactor y Dios se lo contó como justo. ${ }^{69}$ Por lo tanto, la confianza de Abram no estaba depositada tanto en la promesa de descendencia sino en Dios como protector y benefactor. ${ }^{70}$

El segundo tema se relaciona con la elección y las promesas de Dios. Estas últimas son mencionadas en los vv. 1, 4, 5, y están dadas en función de una elección anterior (12:1). Pero, aunque las promesas se pueden distinguir entre sí ("yo soy escudo para ti", "tu recompensa incrementaré", "quien vendrá de tus entrañas, éste te heredará", "así llegará a ser [tu] descendencia"), todas están integradas en una sola que se enmarca en los propósitos salvíficos de Dios quien es no sólo el que promete sino también el garante de dichas promesas. Abram ha sido elegido para formar parte del plan de Dios para salvar al hombre. Y, por lo tanto, se convierte en el depositario de las promesas divinas que apuntan a esa realización del plan. No hay mérito de Abram en esto. Pero, éste va creyendo progresivamente en que tales promesas se realizarán. ¿Cómo será posible eso si Abram no tiene hijos? Él no lo sabe, pero confía en las promesas.

Un tercer tema destacado es el de la simiente o descendencia. Abram está preocupado básicamente por la posibilidad de tener un hijo (lo que está implicado en las

sucesores de ambos debían mantener la continuidad de los términos del pacto firmado por sus antecesores. Véase Mendenhall, "Covenant Forms in Israelite Tradition", 69-60.

${ }^{69}$ Cairus, "Protection and Reward", 404.

${ }^{70}$ Ibíd., 404-405. 
promesas de Dios a Abram en Gén 12:2, 3). Pero el texto sugiere que Dios atiende la preocupación de Abram en función de un plan que lo trasciende. Ese plan es el del surgimiento (o continuidad) de un linaje escogido, tema que atraviesa todo el Génesis. De este linaje escogido surgirá el Salvador del mundo (Gál3:16) y en ello radica su importancia. Aunque al principio Abram está preocupado por su simiente, en términos de un hijo, progresivamente parece comprender que el plan de Dios va mucho más allá de eso. Es verdad que en el v. 4 Dios le promete que será alguien de sus entrañas el que lo heredaría. Pero a continuación (v.5) Dios habla dela descendencia de Abram en términos de multitud. Una multitud que Abram no podrá contemplar porque moriría antes (v. 15) pero para la cual Dios tiene un propósito (ver vv. 13-21). Abram, sin embargo, se conforma con la promesa de tener un hijo que sin duda será un anticipo visible de la simiente en sentido amplio. En verdad el hijo es la condición para que dichas promesas tengan pleno cumplimiento. En ese sentido, Abram no verá el pleno cumplimiento de las promesas de Dios (véase Heb 11:40) a pesar de que confiaba en que su simiente sería como las estrellas del cielo.

Un cuarto tema es el de la fe. Parece claro a partir del texto que el asentimiento de Abram a las promesas divinas fue progresivo ("creía", v. 6). Esta fe progresiva fue creciendo en función de la interacción entre Dios y Abram. Por otro lado, esta fe no es ajena a toda evidencia. Dios le muestra el cielo a Abram y le dice que su descendencia será como las incontables estrellas. ${ }^{71}$ Pero la confianza de Abram no se limitaba a

${ }^{71}$ De hecho, en el v. 7 Abram, de quien se dijo que "creía" en el v. 
las promesas de descendencia. Su fe es una reacción a la invitación de parte de Dios de confiar en él como su protector y benefactor. ${ }^{72}$ Esto le permite a Pablo utilizar Gén 15:6 para explicar que la justificación del creyente es sólo posible por la fe y no por obras (Rom 4) y, por lo tanto, los gentiles pueden ser linaje espiritual de Abram debido a que también son justificados por la fe salvadora que Abram ejerció (Gál 3:6).

Un cuarto tema ligado al anterior es el de la justicia acreditada. A Abram se le computó justicia en función de su confianza sostenida en que Dios cumpliría con sus compromisos pactuales. No es resultado de un mérito intrínseco de Abram sino un don de Dios pero que le es computado o atribuido a Abram como resultado de la fe ejercida por éste. Esta justicia implica que Abram se encuentra en una correcta relación con Dios. Esa relación correcta con Dios le permitió formar parte de los designios salvíficos de Dios.

\section{A modo de conclusión}

¿En qué creyó Abram? El texto de Gén 15:6 se entiende mejor a la luz de su contexto inmediato (vv. 1-5). Abram "creía" o asentía a la propuesta pactual de Dios quien le ofrece ser su protector y benefactor a la vez que garantiza dicho pacto a través de una promesa de descendencia. Por otro lado, queda claro que la fe de Abram se sostuvo a través del tiempo gracias

6, pide una señal que confirme su fe (“¿en qué conoceré ...?), sin que esto signifique un menoscabo en su fe.

${ }^{72}$ Cairus, "Protection and Reward", 396, 397. 
a su estrecha relación con Dios. Por supuesto, este reconocimiento no niega que Abram también creía en la promesa divina en relación a su descendencia tomada no sólo en sentido individual (un hijo) sino en sentido corporativo. Pero ése no es necesariamente el énfasis principal del texto. Abram aceptó los términos del pacto y la garantía ofrecida. Esto implica que la justicia de Abram no le fue computada o acreditada en función de un mérito intrínseco sino en función de su confianza en Dios.

Esta confianza convertiría a Abram en el padre del pueblo de Israel, con el cual Dios estableció una relación pactual que continuaba la ya establecida con su ilustre antepasado (Éxo 3:6, 14-17; 6:2-8; 19:4-5). Pero más importante aún, Abram se convirtió en el "padre de todos los creyentes", sin importar su raza o nacionalidad, "a fin de que también a ellos la fe les sea contada por justicia" (Ro 4:11; véase Gál 3:6) en el contexto del nuevo pacto (Heb 8:8). Al igual que en la experiencia de Abram, quienes "siguen las pisadas de la fe" del patriarca (4:12) encontrarán plena seguridad y galardón en Aquel que siempre cumple sus promesas. : 